\title{
Tissue Ghanges in the Adult Tryptophan-deficient Rat
}

\author{
By ANNE S. COLE \\ Department of Physiology, University of Bristol \\ AND PATRICIA P. SCOTT* \\ Department of Physiology, Royal Free Hospital School of Medicine, London, W.C. I \\ (Received 20 October 1953)
}

In early studies histological methods were largely empirical and thus unequal to the demonstration of changes that must have existed in the tissues of animals on deficient diets. Thus, although Willcock \& Hopkins (1906) did not observe any histopathological changes in the young tryptophan-deficient mice used in their classical experiments, moribund adult rats maintained on a tryptophan-deficient diet for more than roo days (Cole \& Robson, I95I) were in such poor condition that it seemed possible that changes, detectable by the improved techniques now available, might have occurred in their tissues. Though some histological methods may be considered reliable within specified limits from a qualitative point of view, agreement with quantitative chemical estimations is not always satisfactory and it seemed useful to carry out such a comparison for proteins, fats and glycogen in the liver of deficient and control rats in a further experiment.

The results of the preliminary and main investigations showed that the organs of adult rats most affected by prolonged tryptophan deficiency were, firstly, the liver, gonads and endocrine glands, i.e. organs having a secretory function and high metabolic turnover, and secondly, tissues with a high rate of replacement, particularly epithelia and blood. Albanese \& Buschke (I942) and Albanese, Randall \& Holt (I943) showed that in young rats continuously growing structures, such as epithelia and reproductive organs, bear the brunt of tryptophan deficiency. Severe signs were more rapidly manifest in their weanling rats than in the adult rats described here, which were used to avoid complications introduced by failure of growth.

\section{EXPERIMENTAL}

General. Three adult female Lister strain rats (nos. II3, II 5 and II6) used in the preliminary investigation were described by Cole \& Robson (195r) and had been rendered tryptophan-deficient on an acid-hydrolysed casein diet, given for 106-1 12 days. The diet contained: casein (whole or hydrolysed) 14.7 , cystine 0.3 , starch 62 , hardened arachis oil 15 , lard 3 and salts 5 parts by weight. Each rat was given daily I $\mathrm{ml}$. yeast extract ( $\equiv 500 \mathrm{mg}$ yeast), $30 \mu \mathrm{g}$ thiamine hydrochloride, $30 \mu \mathrm{g}$ pyridoxin, $50 \mu \mathrm{g}$ riboflavin, $100 \mu \mathrm{g}$ calcium pantothenate, I $\mathrm{mg}$ nicotinic acid, I $\mathrm{mg}$ inositol and $12 \mathrm{mg}$ choline chloride; three drops of cod-liver oil were given five times a week and three drops of mixed tocopherols twice a week ( $\equiv 8 \mathrm{mg} \alpha$-tocopherol/week).

In the main experiment the management of the rats was similar although they were

* The contribution is part of thesis for degree of Ph.D in the University of London. 
Wistar strain, and both adult male and female rats were used. They were grouped for even distribution of sex, litter-mates and weight, and fed as follows:

Group I. Six rats received the tryptophan-deficient diet (A.H.C.) ad lib.

Group 2. Six rats received the whole casein $\operatorname{diet}$ (U.C.) but were pair-fed with those of group I. Each rat received the weight of food consumed 2 days previously by its pair mate in group $\mathbf{I}$.

Group 3. Six rats received $a d$ lib. $\operatorname{diet}$ A.H.C. supplemented with an inadequate amount of tryptophan (0.01 \%).

Group 4. Four rats received ad lib. diet A.H.C. supplemented with an adequate amount of tryptophan ( $0 \cdot 2 \%)$.

Group 5. Four rats received ad lib. the whole-casein diet (U.C.).

Group 6. Four rats received $a d l i b$. the stock diet.

Group P.D. Three rats received ad lib. a protein-free diet (P.D.).

Group P.D. is included, although these animals were from another experiment in which the treatment of the animals differed in minor respects. For part of the experimental period these three animals were kept together in a metabolism cage instead of individually, but the principal difference was that the diet was uncooked and the vitamins were added directly to the dry diet in the following quantities: thiamine hydrochloride 4, pyridoxin 4, riboflavin ro, calcium pantothenate 20, nicotinic acid 100, inositol 100, choline chloride $1000 \mathrm{mg} / \mathrm{kg}$, and yeast extract $100 \mathrm{ml} . / \mathrm{kg}$.

Histological methods. The animals were killed under ether anaesthesia of short duration by draining blood from the femoral vessels and opening the thorax. The liver and spleen were weighed in the fresh condition. The organs examined histologically included the alimentary canal, liver, kidneys and spleen, pancreas, adrenals, thyroid and pituitary, female reproductive organs, voluntary muscles of the neck, skin and tail and the central nervous system.

In the preliminary experiment the tissues were fixed in Bouin's fluid or formolsaline, embedded in paraffin wax, sectioned at 5 and $10 \mu$, and stained routinely with Scott's haematoxylin and Biebrich scarlet. Additional material taken from more than one lobe of the liver was fixed in formol-saline and sectioned on the freezing microtome. It was then stained with Sudan black (Baker, 1944) and safranin for lipids.

The pituitary was stained with Mann's methyl-blue eosin, and Weil's method was used for the brain and spinal cord. Sections of liver, spleen and skin were treated with potassium ferrocyanide and hydrochloric acid, for ferric ions.

In the main experiment blood samples were taken for erythrocyte counts and for haemoglobin, packed-cell volume and plasma-protein estimations. Tissues were fixed in formol-calcium (Baker, 1944) and post-chromed or fixed in Helly's (1903) fluid, embedded in paraffin wax and stained routinely as before. The pancreas was sectioned serially and stained for islet tissue (Palay \& Lazarow, 1946). Adjoining slices of liver 2- $3 \mathrm{~mm}$ thick were fixed $(a)$ in $80 \%$ ethanol, cut in paraffin at $4 \mu$ and stained with gallocyanin (Lagerstedt, 1947) for nucleoproteins and by Gomori's (194r) technique for alkaline phosphatase, $(b)$ in Gendre's fluid (Lison, 1936), cut at $7 \cdot 5 \mu$, and stained with Best's carmine and haematoxylin for glycogen, and with potassium ferrocyanide 
and hydrochloric acid for ferric ions, and $(c)$ in Helly's fluid and post-chromed for mitochondria (Cain, 1948). Liver and adrenals fixed in formol-calcium were cut frozen at $5 \mu$ after embedding in gelatin and stained with Sudan black or carbol Sudan III (Jackson, 1944) for lipids. The relative volumes occupied by various cell components in the liver sections were determined by the method of Chalkley (1943) which yields statistically valid results on uniform tissues such as the liver.

Chemical methods. A weighed portion of the fresh liver was analysed for glycogen (Kosterlitz, 1933) and the remainder dried at $100^{\circ}$ to constant weight. It was then ground to a fine powder, which was used for the fat and nitrogen estimation.

The nitrogen determinations were carried out on $0.1-0.2 \mathrm{~g}$ samples of dried liver powder, using the ordinary Kjeldahl method. The protein content was calculated by applying the conversion factor of $6 \cdot 25$. No allowance was made for non-protein nitrogen.

In the fat estimations $0.2-0.5 \mathrm{~g}$ dried liver powder was exhaustively extracted with absolute ethanol followed by diethyl ether. The extracts were evaporated and the residue extracted with boiling light petroleum and centrifuged. The petroleum extract was quantitatively transferred to a weighing bottle, the petroleum evaporated and the extracted lipid weighed.

\section{RESULTS}

\section{Preliminary experiment}

General. The tryptophan-deficient rats showed the usual features associated with chronic protein deficiency, namely emaciation, staring coat, anorexia, permanent dioestrus, anaemia, and oedema of the extremities (Cole \& Robson, 195I). Features that appeared to be specific results of tryptophan deficiency were caudal necrosis, staining of the wrists, paws and nose with reddish material probably of a porphyrin nature, and nervous signs which included lethargy, atonia, hyperexcitability and tremors. The average loss of body-weight was $54 \%$ and the average food intake fell from $86 \mathrm{~g}$ for the Ist week of the deficiency period to $5 \mathrm{I} \mathrm{g}$ in the last week.

Epithelial tissues. The epidermis of the abdominal skin was thin, and that of the necrotic tails showed extensive sloughing. Two out of the three rats showed a reduction in the width of the oesophageal epithelium with sloughing of the superficial layers. In the duodenum the epithelial cells of the villi appeared cuboidal instead of columnar and in the ileum many of the villi were eroded, in places as far as the crypts of Lieberkuhn $(\mathrm{Pl} .2,3)$ giving the mucosa a shorn appearance with necrotic cellular debris in the intestinal lumen. The remaining epithelial cells were low and granular with an ill-defined striated border and the cells of the crypts had ragged margins as had the epithelial cells of the large intestine. Epithelial cells lining the reproductive tract also were reduced in height, and the cells lining the Fallopian tube bore only occasional cilia.

Digestive glands. Throughout the intestines there was a marked reduction in the number of goblet cells, and Brünner's glands were low with irregular margins. The gastric mucosa was normal. Acinal cells of the pancreas were smaller and contained fewer secretory granules than in normal animals and the lining of the ducts was N virl 2 
squamous rather than cuboidal in type. Liver weight was reduced to $2 \cdot 35 \%$ of the initial body-weight compared with $3 \cdot 2 \%$ for rats on the stock diet. The lobules of the liver were small, but showed normal amounts of connective tissue. An apparent increase in the density of the nuclear population was due to reduction in the cytoplasm of the parenchymal cells, particularly in the centre of the lobule. Round the portal tracts the arrangement of the sinusoids was irregular and the cytoplasm of the cells in the periportal areas had a poor affinity for acidophil dyes. In frozen sections the cells were found to contain many small, and a few larger droplets of fat, and occasionally cells had coalesced to form characteristic lipodiastaemata (Hartroft, I950) (Pl. I, I). Fine iron granules giving the Prussian-blue reaction were present in almost every parenchymal cell, often in considerable numbers. The parenchymal nuclei had exceptionally well-defined nuclear membranes and large conspicuous nucleoli (Pl. I, 2).

Muscle. Smooth muscle was normal throughout the alimentary canal and female reproductive tract. Voluntary muscle of the neck and tail was reduced in cross-sectional diameter and had a poor affinity for stain. Cardiac muscle was not examined.

Endocrine organs. The secretory cells of the thyroid gland were low and irregular with poorly staining nuclei. The colloid vesicles were unequal in size and one animal showed hypertrophy of fibrous connective tissue. Pancreatic-islet tissue was apparently increased, although the material was insufficiently studied to be certain on this point. The adrenal glands, on the other hand, were reduced in size, reduction particularly affecting the cortex. No gross changes were seen in the pituitary, but the ovaries were small with the cytoplasm of the stroma and interstitial cells markedly reduced. Large atresic corpora lutea were present but only a few very small follicles.

Other organs. The spleen was reduced in size and averaged only $0.07 \%$ (two rats) of the initial body-weight compared with $0.21 \%$ in rats on the stock diet. Both red and white pulp were diminished, rendering the trabecular tissue very conspicuous. Nuclei, especially of the lymphocytes, had a reduced affinity for stain and active lymph nodes were almost entirely absent. Lymphoid tissue was also deficient in the alimentary canal. Abundant macrophages filled with yellow-brown granules, which were found to be haemosiderin, were present in the spleen, liver and skin.

No evidence of degeneration was observed in the myelin sheaths in the principal tracts of the central nervous system, neither was any abnormality found in the kidneys.

\section{Main experiment}

General. Although the rats of group I took longer to reach the terminal stages of tryptophan deficiency than those of the preliminary experiment, their general condition was similar except that there was no caudal necrosis or obvious oedema. Their poor coats, listless behaviour and loss of appetite were in marked contrast to those of their pair-fed controls, which were thin, active and so hungry that they became fierce and difficult to handle; they consumed all their food as soon as it was given to them.

Blood analyses (Table I) showed a fall in the haemoglobin level, erythrocyte count, packed-cell volume and plasma proteins of the tryptophan-deficient groups I and 3 , the reduction being slightly greater in the females than males. In the pair-fed group 
the values were intermediate between the deficient groups and group 4, fed on the whole-casein diet ad lib.

Liver. The results of the histological and chemical investigations of the livers of the seven groups of animals are shown in Table 2. The greatest reduction in liver weight, expressed as a percentage of the initial body-weight, occurred in the pair-fed caloriedeficient controls. Similar but slightly smaller reductions occurred in the tryptophandeficient, low-tryptophan and protein-deficient animals.

A slight increase occurred in the water content of the livers of the tryptophandeficient, pair-fed and low-tryptophan groups, and a definite reduction in the proteindeficient group; the results of the other liver analyses are therefore expressed on a dry-weight basis. Shrinkage of the parenchymal cells of the tryptophan-deficient rats (P1. I, 3) with a marked loss of cytoplasm was shown by a Chalkley (1943) analysis carried out on liver sections from groups $I_{2} 2$ and 5 (Table 3 ). The reduction in cytoplasm relative to the nucleus was less marked in the calorie-deficient controls. Random measurements with an eye-piece micrometer suggested that the nuclei of the parenchymal cells of the tryptophan-deficient group were rather larger than those of the pair-fed controls, although the number of observations was insufficient for statistical treatment. The ratio nucleolus: nucleus volume was increased in the tryptophandeficient rats compared with the whole-casein group 5, and a small increase also occurred in the pair-fed controls. The ratio of the volume of the Küpffer-cell nuclei to parenchymal nuclei fell in the tryptophan-deficient rats, when compared with the pair-fed and ad lib. fed whole-casein controls (Table 3; Pl. I, 3, 4). This fall could be accounted for either by enlargement of the parenchymal nuclei or shrinkage of the Küpffer-cell nuclei, or by a reduction in the number of Küpffer cells per unit volume of liver tissue.

The cytoplasm of the parenchymal liver cells of the tryptophan-deficient rats of group I had a poor affinity for acidophil dyes and was vacuolated, with optically empty spaces round the nucleus, and ill-defined cell margins (Pl. I, I, 3). Similarly in the protein-deficient rats the cytoplasm, lying around or between large fat vacuoles, had lost its affinity for acidophil dyes. In the pair-fed group 2 the cytoplasm was in marked contrast, being dense, intensely acidophil, and without vacuoles, staining evenly, with cell outlines clearly defined (Pl. I, 4).

The appearance of the cytoplasm was related to the protein content of the livers (Table 2). In the tryptophan-deficient rats the value of $\mathrm{N} \times 6.25$, expressed as a percentage of dry weight, was 65.5 , and the mean value for the pair-fed control group was $79.4 \%$. Since percentage values are materially affected by the fat and glycogen present, a better measure of the protein content was obtained by relating the absolute amount of protein in the liver to the initial body-weight; the value was $0.34 \%$ for the tryptophan-deficient and $0.36 \%$ for the pair-fed control rats. Thus, the total amounts of protein present were comparable in spite of large percentage differences. Similarly, although the livers of the protein-deficient group contained only $42 \cdot 9 \%$ protein, the mean protein content based on the initial body-weight was $0.28 \%$. The mean total protein percentage was slightly higher in the livers of rats that had received an inadequate tryptophan supplement. The liver cells of the adequately nourished animals 


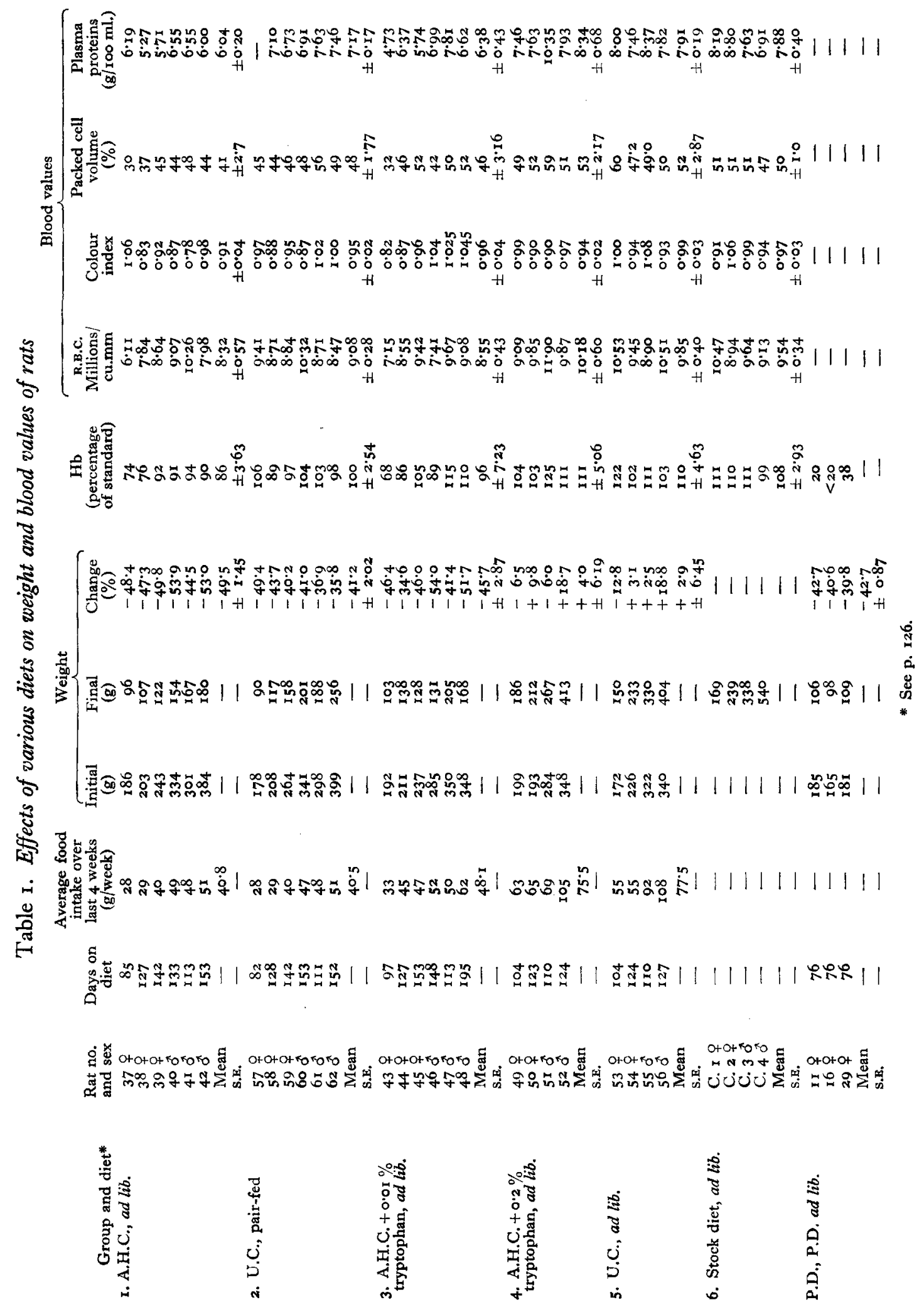




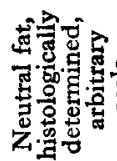

namnno

Q

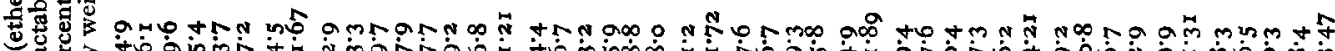

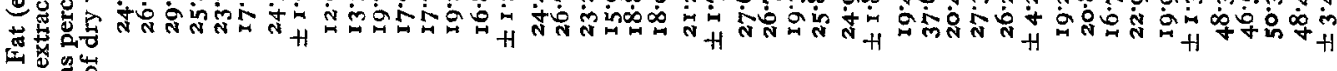

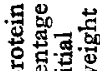

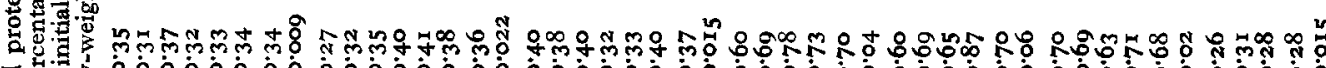

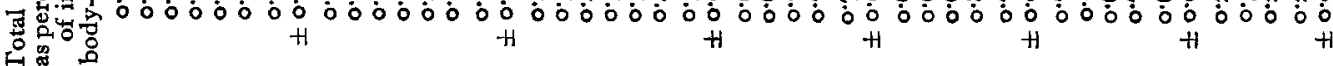

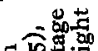

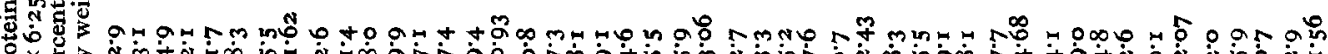

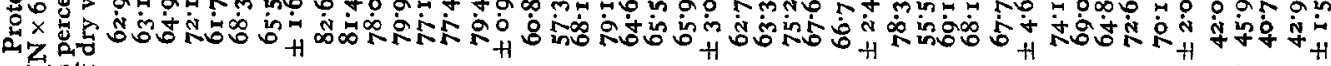
gू

.2

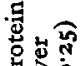

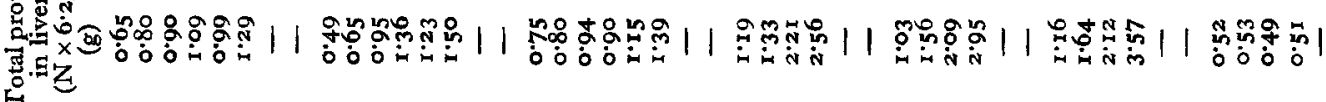

o'

F

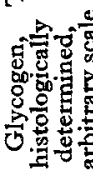

รี

A

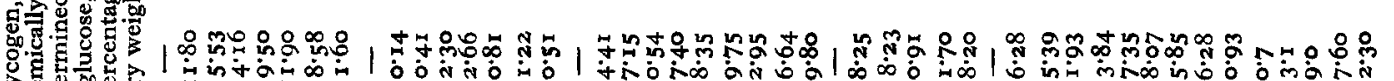

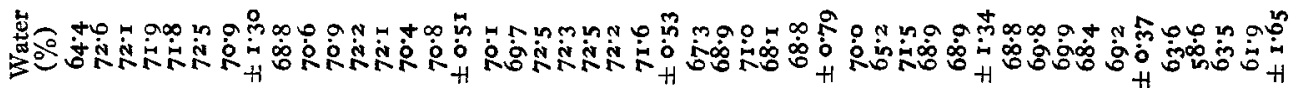

โกิ 
of groups 4,5 and 6 were large (P1. 2, I) and the cytoplasm densely acidophil. Nevertheless, the percentage of protein was not much greater than in the completely and relatively tryptophan-deficient animals although, when the amounts were related to the initial body-weights, these controls were found to contain about twice as much liver protein (Table 2).

Mitochondria of the liver parenchyma in the tryptophan-deficient group were reduced, misshapen, swollen and clumped together, instead of being evenly distributed throughout the cytoplasm. In the pair-fed controls swelling and clumping of mitochondria mentioned by Cameron (1952) as following inanition and other kinds of experimental injury were also observed, but the mitochondria were far more numerous than in the tryptophan-deficient rats. Cytoplasmic basophil inclusions (ribonucleo-

\section{Table 3. Results of examination of sections of livers of rats by Chalkley's (1943) method}

(Counts made on material fixed in Gendre's fluid and stained with haematoxylin and Biebrich scarlet)

Group and diet

I. A.H.C., ad lib.

2. U.C., pair-fed

5. U.C., ad lib.

Volume ratio
of cytoplasm
to nucleus
$3 \cdot 15$
$3 \cdot 15$
$3 \cdot 29$
$3 \cdot 53$
$3 \cdot 26$
$2 \cdot 79$
$3 \cdot 19$
$\pm 0 \cdot 099$
$4 \cdot 20$
$4 \cdot 62$
$4 \cdot 66$
$4 \cdot 65$
$4 \cdot 82$
$4 \cdot 00$
$4 \cdot 49$
$\pm 0 \cdot 130$
$8 \cdot 37$
$8 \cdot 25$
$8 \cdot 47$
$8 \cdot 10$
$8 \cdot 30$
$\pm 0 \cdot 079$

Volume ratio of

Volume ratio Küpffer nuclei of nucleolus to parenchymal to nucleus

$0.250 \quad 0.193$

$0.284 \quad 0.183$

$0.187 \quad 0.230$

$0.227 \quad 0.173$

$0.240 \quad 0.153$

$0.273 \quad 0.137$

$0.244 \quad 0.178$

$\pm 0.014 \quad \pm 0.013$

$0.070 \quad 0.33^{6}$

$0.140 \quad 0.294$

$0.146 \quad 0.257$

$0.096 \quad 0.350$

$0.083 \quad 0.35 \circ$

$0.133 \quad 0.287$

$0.111 \quad 0.312$

$\pm 0.013 \quad 0.016$

$0.103 \quad 0.502$

$0.067 \quad 0.386$

$0.090 \quad 0.387$

$0.073 \quad 0.544$

$0.083 \quad 0.455$

$\pm 0.008 \quad \pm 0.040$

protein) were not seen in the parenchymal cells of any rat of group I (Pl. I, 3) or group P.D. and traces only were found in the rats of groups 2 (pair-fed controls, P1. I, 4) and $3(0.01 \%$ tryptophan). They were very conspicuous, however, in the livers of rats of groups 4 (Pl. I, I), 5 and 6, fed on adequate diets.

Histologically demonstrable alkaline phosphatase was present in the nuclei of liver cells of group I, in slightly greater amounts than in the other groups.

Some granules stainable by the Prussian-blue reaction for ferric ions were present in the parenchymal cells of group $\mathrm{x}$, but were fewer than in rats of the preliminary experiment, in which the degree of anaemia was considerably greater (Cole \& Robson, I95I). Granules were present in some of the Küpffer cells and in large phagocytes 
surrounding the portal tracts in the protein-deficient animals, which were grossly anaemic. Inorganic iron was not found in the parenchymal cells of the pair-fed controls in which the haemoglobin values were only slightly below normal (Table r).

The amount of glycogen in the liver of the rats of the groups I, 3 and P.D. varied from moderate to considerable (Table 2). Variations occurring within the groups may have been due to differences in food consumption immediately before killing. The glycogen content of the livers of the pair-fed group was very low, but that of the adequately nourished rats of groups $4-6$, with the exception of one rat, fell within the normal range. Histological findings are expressed in the table on an arbitrary scale, in which $O$ represents the absence of histologically detectable glycogen, and 4 the maximum amount seen; these can be compared with the chemical estimations, the results showing good agreement.

Histologically detectable fat was present in frozen sections of the liver of all but one of the tryptophan-deficient rats, and in this animal the fat content was also low by chemical estimation (Table 2). Fat appeared as black-staining droplets of variable size within the cytoplasm of the parenchymal cells nearest to the portal canals (Pl. 2, 2) and the average fat content was $24.5 \%$ (dry weight). The pair-fed controls, which showed no stainable neutral fat, although phospholipids, staining grey, were still present, had an average fat content of only $16.8 \%$. Female rats that received $0.01 \%$ tryptophan had about as much fat as the wholly deficient rats, whereas the males had less fat and were more comparable with the calorie-deficient group. The protein-deficient animals showed exceptionally high values for liver fat, equivalent to nearly half the dry weight of the liver, or approximately double the amount in the tryptophan-deficient group. All the parenchymal cells in this group contained fat droplets, fine in the centrilobular regions, larger in the mid-zone, and in the periportal regions coalescing to push the nucleus to the periphery of the cell. These fat-laden cells had occasionally broken down to form lipodiastaemata. With the exception of group 3 the agreement between the histological and chemical evaluations of lipid was satisfactory.

Other tissues. The histopathology of the tryptophan-deficient rats of group I was similar in all respects to that of the animals examined in the preliminary experiment. Except for the spleen and adrenals, where the changes were comparable to, but less severe than, those seen in group $x$, the tissues from the pair-fed controls of group 2 resembled those of the whole-casein controls fed ad.Jib., and could thus be considered normal.

In spite of the partial loss of villi and presence of necrotic areas in the intestinal mucosa of the tryptophan-deficient rats, there was no evidence that absorption of foodstuffs was seriously impaired. The faeces were normal and the glycogen contents of the livers of these animals were comparable with those of the control rats fed on the stock diet. No abnormalities were observed in the intestines of rats in the other groups.

The individual acinar cells and lobules of the pancreas of the tryptophan-deficient rats were smaller than those of the pair-fed controls. Necrosis was seen in some parts of the gland accompanied by infiltration with lymphocytes and, in some cases, eosinophils. The increase in the proportion of islet tissue seen in the preliminary experiment 
was again observed. Although this increase was partly due to the reduction of the exocrine tissue, the islets were so large that it seemed likely that some hypertrophy had occurred as well.

The adrenals of the rats of groups $1-3$ were very much smaller than those of the adequately fed rats of the other groups. The amount of sudanophil fat in the cortex showed great individual variation, but this could not be correlated with any particular diet.

Various stages of degeneration were found in the testes which were withdrawn from the scrotal sacs in the tryptophan-deficient male rats. Spermatogenesis was arrested in one animal and desquamated giant cells showing stages of division were present in the lumen of the tubules. In the other two male rats spermatids were fused in groups and the number of normal spermatozoa was reduced. The epithelial cells of the epididymis of all these animals were vacuolated and had lost their cilia. The reproductive organs of the pair-fed control rats were normal.

\section{DISCUSSION}

Since the effects of the acid-hydrolysed casein diet in the preliminary experiment could have been attributed to anorexia and consequent calorie deficiency, rather than to tryptophan deficiency, it was necessary to introduce controls in the main experiment. Anorexia could have been overcome by force-feeding the rats with calorically adequate amounts of the acid-hydrolysed casein diet, a method found by Spector \& Adamstone $(\mathrm{r} 95 \circ a, b)$ to accentuate the effect of tryptophan deficiency in young rats, drastically reducing the time required for the production of acute symptoms. The behaviour pattern of the force-fed animals was, however, unlike that of rats allowed to eat a tryptophan-deficient diet at will; they were hyperexcitable, subject to severe convulsive fits and showed acute discomfort after the administration of the diet (by stomach tube) with tenderness of the abdomen, bloating and diarrhoea, and after death the intestines were distended with liquid and gas. Thus, digestion of the force-fed diet was obviously unsatisfactory, suggesting that pair-feeding would be the better method of assessing the effects of inanition. The effects of tryptophan deficiency were, in fact, found to be quite unlike those resulting from underfeeding with a qualitatively adequate diet. The pair-fed controls were alert, active and vicious, in contrast to the apathetic, lethargic, shivering tryptophan-deficient rats.

Examination of the liver at three levels of organization, histological, cytological and chemical, revealed abnormalities unlike those produced by inanition on a calorically inadequate diet, or on a low-protein diet. Loss of weight, reduction in the volume of parenchymal cells and poor affinity for acidophil dyes all indicated loss of substance from the tryptophan-deficient liver, manifest at the chemical level by a marked fall in nitrogenous constituents, particularly evident when related to initial body-weight (Table 2). Kosterlitz (1944, 1947) observed a fall in the nucleic-acid content of the liver of rats on an acid-hydrolysed casein diet when estimated chemically. Since it has been shown that microsomes and mitochondria carry over $70 \%$ of the ribonucleoprotein of the liver cell between them (Schneider, 1948; Hogeboom, Schneider \& Pallade, 1948), loss of basophilic cytoplasmic inclusions (microsomes) and reduction 
and distortion of mitochondria (also noted by Spector \& Adamstone, I950 $b$ ) in the liver of the tryptophan-deficient rats is in agreement with Kosterlitz's findings at the chemical level. The mitochondria of normal liver cells carry the enzymes associated with the cytochrome and tricarboxylic-acid systems (Schneider, I946; Bourne, 1953) and fatty-acid oxidases (Schneider, 1948; Kennedy \& Lehninger, 1949), whereas the microsomes have a high dipeptidase activity. Loss of these intracellular bodies may, therefore, account for the marked depression in the rate of respiration of liver homogenates from tryptophan-deficient rats observed by Williams \& Elvehjem (1950), a result not obtained from livers of rats fed on low-protein or methionine-deficient diets (Williams, Denton \& Elvehjem, I949). Williams, Feigelson \& Elvehjem (I950) also showed that tryptophan is essential to the rat for the maintenance of a normal level of pyridine nucleotide in the liver and cannot be replaced by dietary nicotinamide for this purpose. Additions of tryptophan to a non-protein diet significantly increased the ability of rat-liver homogenates to synthesize phosphopyridine nucleotides (Williams, Feigelson, Shaninian \& Elvehjem, r95I). Thus tryptophan plays an important part in the maintenance of enzyme systems of the liver cell, deficiency of this essential aminoacid resulting in modifications of both microscopic structure and chemical composition. Changes in appearance due to accumulation of lipids and, to some extent, of glycogen may be explained on the basis of loss or inactivation of the enzyme systems which normally turn these substances over sufficiently rapidly to prevent any marked accumulation in the liver cell. On this hypothesis the failure of appetite observed in tryptophan deficiency must be regarded as life conserving, intake being steadily reduced to levels at which the liver, and probably other tissues, can continue to turn over the major part of the incoming metabolites. Support for this view is provided by the investigations of Spector \& Adamstone (I950a, b) who found that rats force-fed with a tryptophan-deficient diet had intensely fatty livers and only survived for 16 days compared with the tryptophan-deficient rats described here, which survived more than Ioo days, and showed only slightly fatty livers. Rats on the protein-deficient diet showed, in contrast, severe fatty infiltration even in the presence of adequate supplies of choline, a fact also demonstrated by other workers (Wang, Hegsted, Lapi, Zamchek \& Black, r949; Jaffé, Humphreys, Benditt \& Wissler, r949).

Regressive changes in voluntary muscle of tryptophan-deficient rats, including loss of affinity for acidophil dyes and reduction by half in the diameter of the fibres, were similar to those observed in the tryptophan-deficient chick by Brown, Wilkening $\&$ Schweigert (1948). Spector \& Adamstone (1950 b), however, found voluntary muscle to be normal in tryptophan-deficient rats, although patchy degenerative areas occurred in cardiac muscle, and in smooth muscle in the gut wall, uterus and bladder. Variation in the effect on different types of muscle might have been due to the effects of forced feeding on their rats.

Reproductive organs are markedly affected by tryptophan deficiency. Vaginal smears from deficient female rats quickly became characteristic of anoestrus (Cole \& Robson, $195^{\mathrm{I}}$ ), and Brown et al. (1948) observed a retardation in the development of oocytes in tryptophan-deficient chicks, although Spector \& Adamstone (I95०b), using a shorter experimental period, did not find any changes in their deficient female rats. 
Regressive changes in the seminiferous tubules were similar to those first observed by Albanese \& Buschke (1942) and later by Spector \& Adamstone (1950b) in tryptophan-deficient rats, also to those reported in deficiencies of phenylalanine, leucine and vitamin $\mathrm{E}$.

The degree of involution observed in the thyroid gland of the tryptophan-deficient rats described was similar to that shown by phenylalanine-deficient rats (Schwartz, Scott \& Ferguson, 195I) and the reduction in the width of adrenal cortex has been paralleled in both phenylalanine and leucine deficiencies (Maun, Cahill \& Davis, I945 $a, b$; Schwartz et al. 195 r). Variations in the appearance and lipid content of the adrenal cortex from stock rats receiving adequate diets are very considerable (Cain \& Harrison, r950), and it was not possible to correlate the distribution of lipids with tryptophan deficiency.

Reduction in the lymphoid tissue of the thymus, spleen and intestines has been observed frequently in animals subjected to inanition (Morgulis, 1923), and since the pair-fed controls showed reduction of the spleen, the changes in the tryptophandeficient animals were probably also due to low food intake. Macrophages, filled with haemosiderin, may have accumulated in the tryptophan-deficient rat owing to failure in the supply of essential amino-acids for the formation of globin, since they suffered from hypochromic anaemia. This type of anaemia can also be produced by diets deficient in protein or in phenylalanine or histidine, but not leucine (Benditt, Wissler, Woolridge, Rowley \& Steffee, I949; Maun et al. I945 $a, b$, 1946).

McCoord, Clausen, Katsampes \& Goff (1947) showed that there was a reduction in serum proteins affecting albumins to a greater extent than globulins, accompanied by a very marked fall in antibody titre in rats that had received an acid-hydrolysed casein diet for 22 days. This finding agrees with the reduction in plasma proteins seen in the rats on the acid-hydrolysed casein, tryptophan-deficient, diet (Table 1 ).

\section{SUMMARY}

I. Examination of tissues from adult rats, rendered tryptophan-deficient by feeding with an acid-hydrolysed casein diet for more than 100 days, showed a reduction in the cytoplasm of epithelial and secretory cells and in the diameter of voluntary muscle fibres, degenerative changes in the testes, hypochromic anaemia and a fall in serum protein.

2. Livers from the tryptophan-deficient rats contained normal amounts of glycogen, but the percentage of fat was higher and the percentage of protein (based on total nitrogen) lower than in the livers of control rats receiving adequate diets. Chemical estimations of these substances agreed well with histological observations.

3. Livers of pair-fed control rats contained little glycogen, minimal amounts of fat and a high percentage of protein. The changes observed in tryptophan-deficient animals could not, therefore, have been due purely to anorexia, and it is suggested that loss of enzyme systems from the liver cells of these animals accounts for their histological appearance, and change in chemical composition.

4. Rats fed on a protein-free diet were anaemic and showed classical fatty livers, with a low percentage of protein. But when total liver protein was recalculated on the 
ANNE S. COLE ANd PATRICIA P. SCOTT. Tissue Changes in the adult
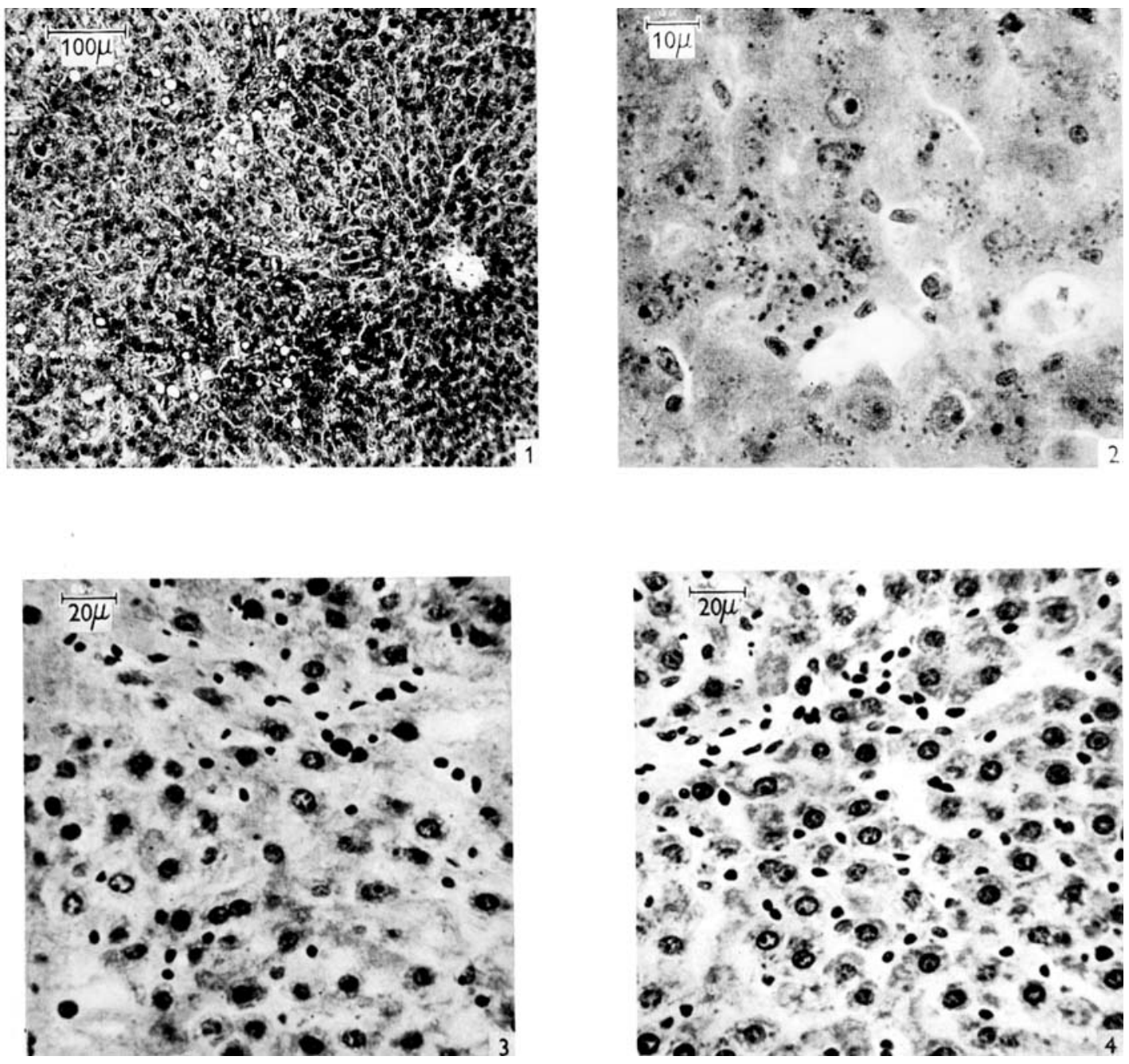

British Fournal of Nutrition, Vol. 8, No. 2 
ANNE S. COLE and PATRICIA P. SCOTT. Tissue Changes In the adult

Plate 2

TRYPTOPHAN-DEFICIENT RAT
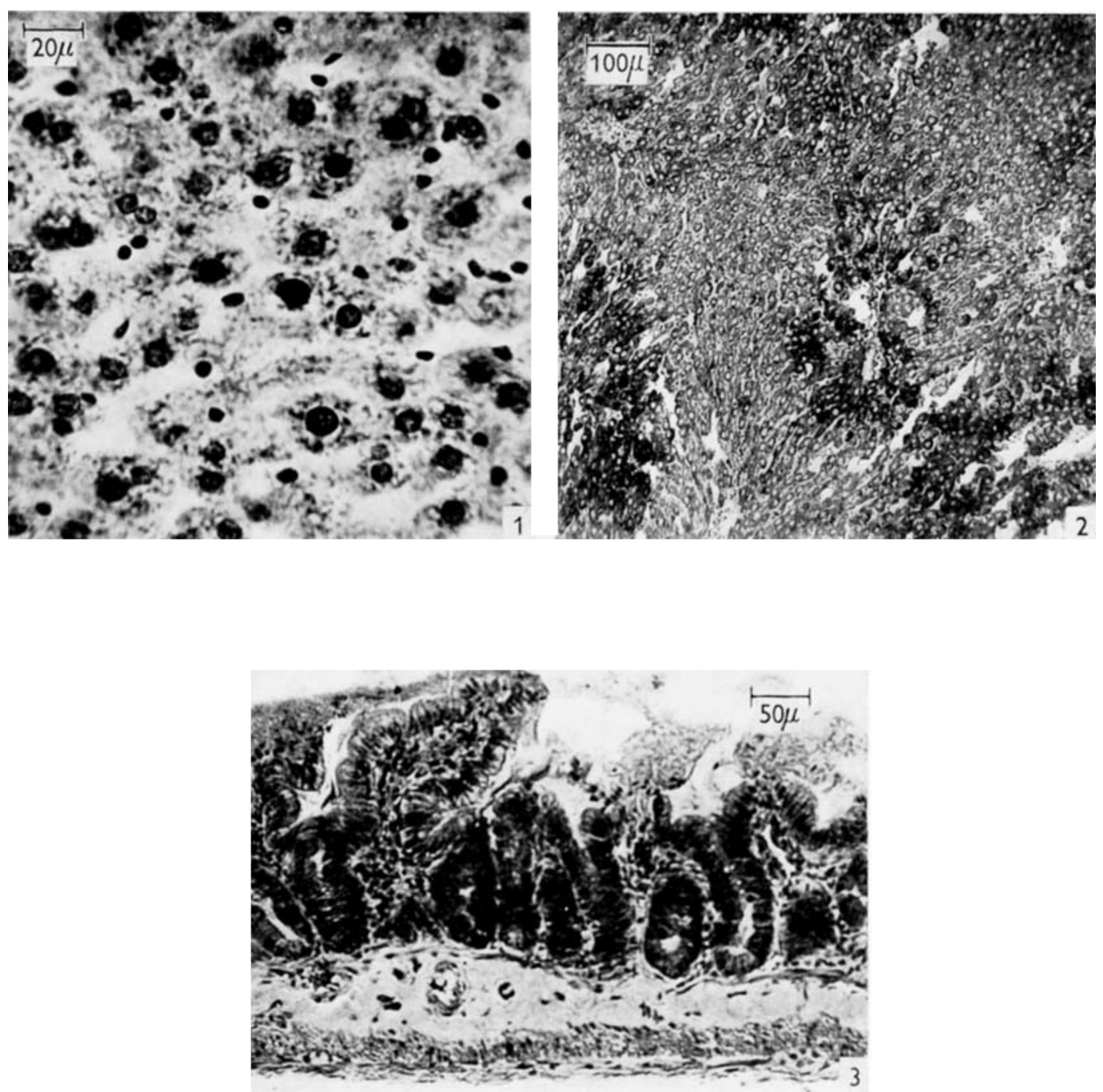

British Fournal of Nutrition, Vol. 8, No. 2 
basis of initial body-weight, values obtained for the tryptophan-deficient groups, pairfed controls and protein-deficient animals did not differ greatly from each other, and were less than half the values obtained for controls on adequate diets.

5. A small supplement of tryptophan, at the rate of one-tenth of the amount present in an adequate diet, did not exert a sparing effect on any individual tissue.

The photomicrographs were taken by J. E. Hutchinson, Department of Dental Medicine, Guy's Hospital, London, S.E. x.

\section{EXPLANATION OF PLATES}

\section{Plate I}

I. Section of liver from tryptophan-deficient rat no. I13, showing shrunken parenchymal cells with uneven staining properties and sinusoids occluded in some regions. Circular empty spaces, filled with fat in life, mark the position of lipodiastaemata. Fixed in Bouin's fluid, embedded in paraffin, stained with haematoxylin and Biebrich scarlet.

2. The same as $I$, but treated with potassium ferrocyanide to show iron, which appears as granules in parenchymal and some Küpffer cells. Nucleoli prominent. Counterstained with safranin.

3. Section of liver from tryptophan-deficient rat no. 40. Cytoplasm reduced, vacuolated, absence of basophil cytoplasmic inclusions, cell margins indefinite. Sinusoids poorly defined. Prominent nucleoli. Fixed in $80 \%$ ethanol, embedded in paraffin, section stained with gallocyanin at $\mathrm{pH} 2 \cdot \mathrm{I}$.

4. Section of liver from rat no. 6o (pair-fed control of rat no. 40). Cytoplasm reduced, basophilic cytoplasmic inclusions absent (granules shown stain only light blue). Cell outlines and sinusoids well defined. Technique as for 3 .

\section{Plate 2}

1. Section of liver from rat no. 52 which had received diet A.H.C. (see p. 126) supplemented with $0.2 \%$ tryptophan. Parenchymal cells of normal size showing purple-staining cytoplasmic inclusions and normal nucleoli. Technique as for Pl. $\mathbf{I}, 3$.

2. Section of liver from tryptophan-deficient rat no. 40 , showing small parenchymal cells, cytoplasm and nucleoli of which appear grey owing to the presence of phospholipids. Cells surrounding portal tracts laden with neutral fat which appears densely black. Fat analysis, $25.4 \%$ dry weight. Fixed in formol-calcium, embedded in gelatine, frozen section stained with Sudan black.

3. Section of ileum from tryptophan-deficient rat no. 113, showing loss of epithelium covering villi. Technique as for P1. I, I.

\section{REFERENCES}

Albanese, A. A. \& Buschke, W. H. (1942). Science, 95, 584.

Albanese, A. A., Randall, R. McI. \& Holt, L. E. Jr. (1943). Science, 97, 312.

Baker, J. R. (1944). Quart. F. micr. Sci. 85, 1.

Benditt, E. P., Wissler, R. W., Woolridge, R. P., Rowley, D. A. \& Steffee, C. H. (1949). Proc. Soc. exp. Biol., N.Y., 70, 240.

Bourne, G. H. (1953). Cytology and Cell Physiology, 2nd ed., p. 238. Oxford: Clarendon Press.

Brown, S. O., Wilkening, M. C. \& Schweigert, B. S. (1948). Proc. Soc. exp. Biol., N.Y., 68, 672.

Cain, A. J. (1948). Quart. F. micr. Sci. 89, 229.

Cain, A. J. \& Harrison, R. G. (1950). F. Anat., Lond., 84, 196.

Cameron, G. R. (1952). Pathology of the Cell, p. 3 ro. London: Oliver and Boyd.

Chalkley, H. W. (1943). F. nat. Cancer Inst. $4,47$.

Cole, A. S. \& Robson, W. (I95I), Brit. F. Nutr. 5, 306.

Gomori, G. (1941). F. cell. comp. Physiol. 17, 71.

Hartroft, W. S. (1950). Anat. Rec. I06, 61.

Helly, K. (1903). Z. wiss. Mikr. 20, 413.

Hogeboom, G. H., Schneider, W. C. \& Pallade, G. E. (1948). F. biol. Chem. 172, 619.

Jackson, C. (1944). Onderstepoort Y. vet. Sci. 19, 169.

Jaffé, E. R., Humphreys, E. M., Benditt, E. P. \& Wissler, R. W. (1949). Arch. Path. (Lab. Med.), 47, 4rI.

Kennedy, E. P. \& Lehninger, A. L. (1949). F. biol. Chem. 79, 957. 
Kosterlitz, H. W. (r933). Arch. exp. Path. Pharmak. 173, 159.

Kosterlitz, H. W. (I944). Nature, Lond., r54, 207.

Kosterlitz, H. W. (1947), F. Physiol. 106, 194.

Lagerstedt, S. (1947). Acta anat. 2, 392.

Lison, L. (1936). Histochimie Animale: Méthodes et Problèmes. Paris: Gauthier-Villars.

Maun, M. E., Cahill, W. M. \& Davis, R. M. (1945a). Arch. Path. (Lab. Med.), 39, 294.

Maun, M. E., Cahill, W. M. \& Davis, R. M. (r945b). Arch. Path. (Lab. Med.), 40, 173.

Maun, M. E., Cahill, W. M. \& Davis, R. M. (1946). Arch. Path. (Lab. Med.), 4r, 25.

McCoord, A. B., Clausen, S. W., Katsampes, C. P. \& Goff, B. L. (1947). Food Tech., Champaign, I, 263 .

Morgulis, S. (1923). Fasting and Undernutrition. New York: Dutton.

Palay, S. L. \& Lazarow, A. (1946). Anat. Rec. 96, 55 .

Schneider, W. C. (1946). F. biol. Chem. 165, 585 .

Schneider, W. C. (1948). F. biol. Chem. 176, 259.

Schwartz, C., Scott, E. B. \& Ferguson, R. L. (195I). Anat. Rec. rro, 3 I3.

Spector, H. \& Adamstone, F. B. (I950a). F. Nutr. 40, 213.

Spector, H. \& Adamstone, F. B. (1950b). Arch. Path. (Lab. Med.), 49, I73.

Wang, C. F., Hegsted, M., Lapi, A., Zamcheck, N. \& Black, M. B. (1949). F. Lab. clin. Med. $34,953$.

Willcock, E. G. \& Hopkins, F. G. (r9o6). F. Physiol. 35, 88.

Williams, J. N. Jr., Denton, A. E. \& Elvehjem, C. A. (1949). Proc. Soc. exp. Biol., N.Y., 72, 386.

Williams, J. N. Jr. \& Elvehjem, C. A. (1950). $¥$. biol. Chem. r83, 539.

Williams, J. N. Jr., Feigelson, P. \& Elvehjem, C. A. (1950). F. biol. Chem. 187, 597.

Williams, J. N. Jr., Feigelson, P., Shaninian, S. S. \& Elvehjem, C. J. (1951). F. biol. Chem. I89, 659.

\title{
Serum Gholesterol and the Diet in Glinically Healthy Men at Slough near London
}

\author{
BY ANCEL KEYS AND MARGARET HANEY KEYS \\ Laboratory of Physiological Hygiene, University of Minnesota School of \\ Public Health, Minneapolis, Minnesota, and Laboratory of Human \\ Nutrition, Churchill Hospital, Oxford
}

(Received 23 October 1953)

It is now clear that the diet has a major influence on the concentration of cholesterol in the blood, but that there are great differences between species. In contrast with the rabbit and the chick, controlled experiments indicate that in man the dietary intake of cholesterol itself is unimportant over the range of possible natural diets (Heymann \& Rack, I943; Messinger, Porosowska \& Steele, 1950; Moses, 1952), but that a rapid and consistent effect is brought about by changes in the total fat intake (Keys, Mickelsen, Miller \& Chapman, r950; Hildreth, Mellinkoff, Blair \& Hildreth, I951; Keys, I952; Pomeranze, Green \& Goldbloom, 1952; Keys, 1953 $a, b$ ). These observations explain the results of clinical trials with diets low in both total fats and cholesterol (e.g. Kempner, 1948; Schwartz \& Merlis, 1948; Chapman, Gibbons \& Henschel, 1950) and the absence of a relationship in surveys in the U.S.A. between cholesterol intake and serum cholesterol (Keys, 1949; Gertler, Garn \& White, I950; Wilkinson, Blecha \& Reimer, 1950).

Such experiments on man are necessarily of limited duration, and the results may be affected by previous dietary habits. The more persistent, long-range relationships between the blood cholesterol and the diet, however, can be studied with suitable 